\title{
SAP ENTERPRISE SOFTWARE IN CURRICULUM INTEGRATION
}

\author{
Roger L. Hayen, Central Michigan University,roger.hayen@outlook.com \\ MonicaC.Holmes, Central Michigan University, monica.c.holmes@cmich.edu
}

\begin{abstract}
The SAP Enterprise Central Component (ECC) Enterprise Software processes more business transactions than any other business software on the planet. Most of the Fortune 1000 companies use SAP software in managing their business operations. Today, students and managers need to become familiar with the software to be more effective in their jobs. A variety of different learning approaches have been utilized, since the introduction of SAP enterprise software into the curriculum of colleges and universities. Recent developments in learning alternatives have provided additional approaches to the design and delivery of an introductory course. One learning strategy has been used in an undergraduate degree program with junior or third year students where a model course content is deployed in the course's delivery. The model course utilizes SAP ECC software transactions with a generally accepted training dataset and continues with an ERPsim simulation that supports learning the application of business analytics and decision-making. A sample of students was surveyed to obtain their perspectives of this model for experiential learning. The results indicate an overwhelming positive reaction to this model course delivery.
\end{abstract}

Keywords: SAP enterprise software, curriculum integration, integrated business processes

\section{INTRODUCTION}

Enterprise software is commonplace in managing business operations [2]. Today's students, managers, and other business employees need to become familiar with this type of software to be most effective in their jobs. Especially critical is the need to understand the enterprise software and its architecture [8]. SAP ECC is an excellent learning platform as it provides knowledge of the type of automated business processing conducted using enterprise software. A variety of different learning approaches have been utilized, since the introduction of SAP ECC enterprise software into the curriculum of colleges and universities in the late 1990's [7, 10]. Those effort focus on the various business process transaction within the SAP ECC software. The College of Business Administration at the authors' university initiated a new course in its common body of knowledge (CBK) curriculum required of all Bachelor of Science in Business Administration (BSBA) degree students in 2006 [5]. This Integrated Business Experience (IBE) course was a two-credit semester offering resulting from a limitation in the total number of credit hours available for a BSBA degree, rather than the desired course content. The course goal is to provide an IBE with students learning the concepts and application of enterprise software and data-driven decision-making. This focus on decision-making extends the reported approaches of others $[1,7,10,14]$. The approach moves student learning experiences outside the typical silos of the functional business areas of accounting, marketing, finance, and management. Experience is obtained in applying cross-functional information to drive decision-making that is available to them with current technology. This is technology that breaks down barriers of merely obtaining information and advances it to providing a focus on how technology permits readily obtaining cross-functional information and then applying it to decision-making.

Over the past 20 years, a variety of datasets have been used in SAP ECC education and training [1]. Since the initial deployment of the IBE course, the SAP University Alliance Program (UAP) expanded the learning materials available for use with courses including the SAP ECC enterprise software [6, 14]. The confluence of all these changes presented an opportunity to refresh the content and delivery of the IBE course in the CBK. The updated learning strategy is one that has been used with junior or third year students in an undergraduate BSBA degree program at the authors' university. Students' reactions to the revision were assessed by surveying their opinions about the course. Results of that survey are presented. They show the course revision has been well received by students and provides a robust learning experience of integrated business processes.

\section{BACKGROUND}

The initial delivery of the IBE course [5] used the SAP ECC Interactive Demonstration and Evaluation System (IDES) dataset together with the Marketplace Simulation. This SAP ECC dataset is used by SAP AG in delivering its various training courses to meet diverse requirements. Those courses are most frequently provided to SAP AG's 
corporate customers who deploy this software in the implementation and ongoing operation of their businesses. It is a large and comprehensive dataset and was the primary dataset available for use in launching the IBE course. The Marketplace Simulation supports student learning that utilizes summarized historical data and an environment for data-driven future-oriented decision-making in a participative environment whereby teams in the course engage in competing with each other. This simulates the highly competitive "real world" business environment. Only a conceptual link was forged between the transaction processing of the SAP ECC enterprise software and the decision-making of the Marketplace simulation. This conceptual linkage was deployed as it appeared to be the best available opportunity for encompassing the integrated concepts of the IBE course at the time of its initial delivery. A survey of students at that time indicated only $55 \%$ were satisfied with their learning experience related to the integration of the conceptual linkage of the SAP ECC transaction processing and the Marketplace Simulation decision-making. Clearly, an opportunity existed to improve student satisfaction with the integration of business process experiences.

Since the initial launch of the IBE course, the learning environment has been simplified by faculty members at several universities guided by SAP AG under its UAP [11]. The UAP is instrumental in developing simplified datasets which are tailored to more focused learning activities within universities. Of the available training datasets, the Global Bike Incorporated (GBI) 2.11 version is the one provided by the SAP UAP to use with student exercises at the transaction level. For this updated IBE course, the GBI experiential learning modules include navigation, organization structure, customer sales order to cash, purchase order to cash, and production planning.

Further, the ERPsim simulator was developed and refined by HEC Montreal [6]. This brings a focus on business simulation [13] entering data that represent business decisions such as product prices and production schedules [3]. The ERPsim simulator runs the underlying individual SAP ECC transactions in a live SAP ECC software instance with its unique dataset or client. It provides summary data in SAP ECC reports with competition among student teams operating different companies through the SAP ECC software. The ERPsim environment is a competitive team-based structure with each team operating a separate company business entity. At the end of a simulated time period, summary data can be downloaded to Excel spreadsheets or Access database software. The data is analyzed by students and new decision values are entered. This development engages students in managerial decision-making [12] use of the SAP ECC software. The decision-making requires critical thinking [9] with the reports providing information to support this decision-making. The IBE course is better designed around the ERPsim simulation with this higher level application for decision-making.

\section{BUSINESS INTELLIGENCE DASHBOARD}

A Business Intelligence (BI) Dashboard provides a number of analytic data views to support data-driven decisionmaking. Some data views are furnished with the ERPsim BI interface while other views maybe created by ERPsim student participants. The BI version of an ERPsim is required to establish a database link with the BI analytics usually developed using Microsoft Excel. With the ERPsim architecture, the BI Dashboard may receive data from the simulation by either of two primary paths.. An automated path requires a separate database server that cast data in Microsoft Access format for transmission to the Excel BI Dashboard. Alternatively, a manual path is available for obtaining report output directly as an Excel file from the SAP ECC client of the simulation. Those Excel files are then input to the Dashboard workbook. Updates are done periodically. They do not occur with the processing of each of the low-level transactions within the SAP ECC system. A dashboard provides information for both internal and external operations. The internal analytics are those that would be available within a typical SAP ECC enterprise software system, whereas the external analytics would most likely be obtained from a third-party collecting and selling marketing data. One arrangement of a dashboard used with the IBE course are as follows:

\section{Internal}

a. Company quantity sold by material (product) (Figure 1)

b. Company quantity sold by material by sales area

c. Company average price by material by sales area

d. Company revenue by material by sales area

e. Company quantity sold by material by sales area by distribution channel

f. Company average price by material by sales area by distribution channel

g. Company revenue by material by sales area by distribution channel 


\section{External}

a. Market average price by material by area (Figure 2)

b. Market quantity sold by material (product)

c. Market quantity sold by material by sales area

d. Market revenue by material by area

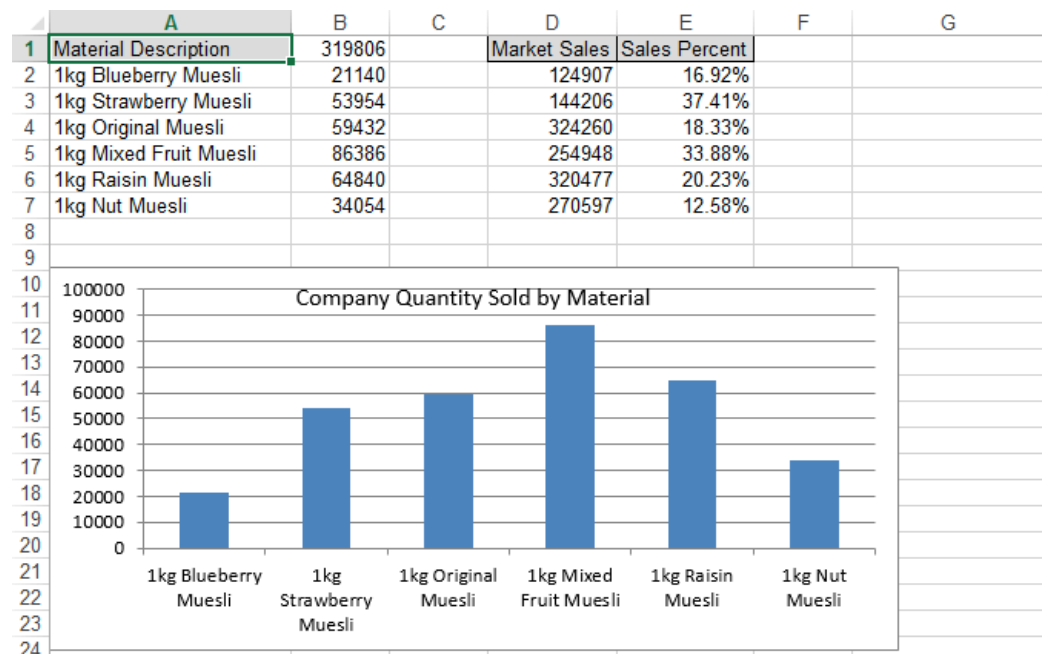

Figure 1. Company quantity sold by material analytics
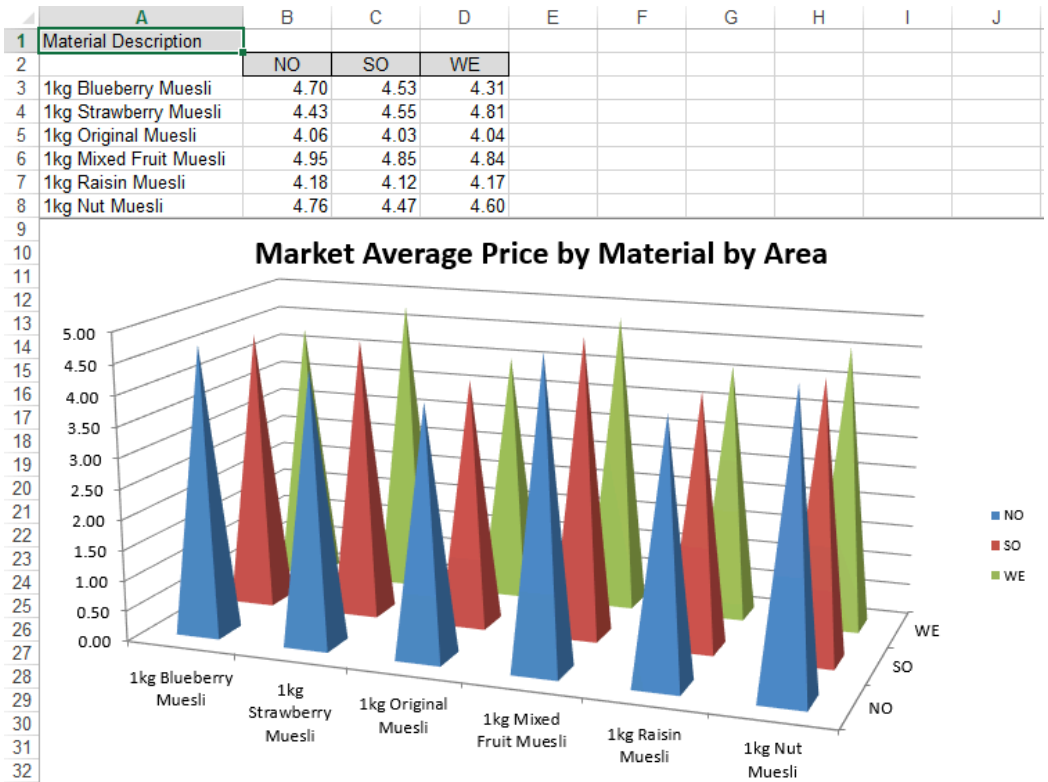

Figure 2. Market average price by material by area analytics

\section{METHODOLOGY}

Using this learning architecture, students in a third year or junior level management information systems course at the authors' university completed the IBE course. A survey of the students' perceptions of the experience was 
administered at the end of the course to three sections of the course. This represents a sample of students from the ongoing population of students enrolled in this course with multiple sections provided each semester. The survey instrument, with 27 questions, uses a seven-point Likert scale with seven (7) as strongly agree/extremely satisfied, one (1) as strongly disagree/strongly dissatisfied, and four (4) as don't know/no opinion. The questions are arranged in four general categories: limited student demographics, overall enterprise software learning, decisionmaking enterprise software learning, and students' other perceptions of the course. The overall enterprise software learning focuses on the individual transactions using the Global Bike 2.11 data. The decision-making software learning focuses on a BI component using the Muesli cereal dataset. The other perceptions are open-ended responses for student comments. Eighty-seven (87) students in the course completed the survey. Course assessment is appraised based on a four-dimension category evaluation [4]. These are described as follows:

1. Business integration is the learning related to the interactions among various business functional areas that include marketing, production, accounting, finance, and management that are included in the SAP ECC software.

2. Business transactions is the learning associated with SAP ECC transaction sets for the various business functions which is the lowest level of the SAP ECC software.

3. Teamwork is the effectiveness of collaborating in teams to complete course activities.

4. Student satisfaction is the student perception of how well they liked the overall SAP ECC experience including the ERPsim simulation.

Several questions collected demographic data while others were open-ended responses. Those questions asked for suggestions to improve the class and the optimal size of a team. Several questions in the survey were reverse coded. Questions on demographic data and open-ended responses are excluded. The remaining set of questions is one where there is not a continuous item numbering of the usable questions. Question 21 is the only question where the 7-point Likert-scale was not used as it directly asked about team size in number of team members. Questions and their reference numbers are presented with their corresponding results in the next section, grouped by the evaluation categories.

\section{RESEARCH ANALYSIS}

Sixty-one (70\%) of the respondents were male while $26(30 \%)$ were female [4]. Table 1 illustrates the results of questions 2, 3, 4, and 15. These questions refer to the impact of the SAP ERPsim on student learning of business functional integration. For the purpose of this evaluation, all the category responses for agree or satisfied are combined to provide a single view of student perceptions. These responses to the questions 2,3 , 4, and 15 indicated that the participants agreed with these viewpoints. This strongly suggests that the students liked using the SAP ECC enterprise software and the SAP ERPsim manufacturing simulation as a tool to learn the integration of business processes. Specifically, these business processes were from the functional areas-accounting, marketing, finance and management.

Table 1. Impact of SAP ECC on Business Integration Understanding

\begin{tabular}{|l|c|}
\hline \multicolumn{1}{|c|}{ Item (Survey question number) } & \% Agree \\
\hline $\begin{array}{l}\text { SAP ECC helped me better understand the integration of the concepts and ideas of } \\
\text { the functional areas of business from marketing, finance and management. (2) }\end{array}$ & 82 \\
\hline $\begin{array}{l}\text { The SAP ERPsim simulations helped me better understand the relationships of } \\
\text { business decision-making among accounting, marketing, finance, and management. } \\
\text { (3) }\end{array}$ & 84 \\
\hline $\begin{array}{l}\text { The SAP ERPsim simulations helped me better understand the issues, concepts, and } \\
\text { ideas of data-driven decision-making that takes place in business enterprises. (4) }\end{array}$ & 90 \\
\hline $\begin{array}{l}\text { Overall, the SAP ECC software and ERPsim assignments helped me to better } \\
\text { understand integrated business processes and data-driven business decision-making } \\
\text { (15) }\end{array}$ & 86 \\
\hline
\end{tabular}


Table 2 indicates student satisfaction with the use of the SAP ERPsim simulator, whereas Table 3 portrays their satisfaction with the SAP ECC enterprise software in their IBE class. More than $82 \%$ of the students reported being satisfied with the use of the SAP ERPsim simulator, the number of SAP ECC assignments and the SAP ERP enterprise software content in their course. It is obvious that the students believed that the SAP ECC enterprise software and the SAP ERPsim are appropriate as learning tools to teach enterprise concepts. This satisfaction appears as a strong positive indicator for a CBK required course.

Table 2. Student Satisfaction with the SAP ERPsim in the IBE Course

\begin{tabular}{|l|c|}
\hline \multicolumn{1}{|c|}{ Item (Survey question number) } & \% Satisfied \\
\hline $\begin{array}{l}\text { Which of the following best describes your overall level of satisfaction with the SAP } \\
\text { ERPsim simulations used in the SAP ERP course in understanding integrated business } \\
\text { processes? (6) }\end{array}$ & 82 \\
\hline $\begin{array}{l}\text { Which of the following best describes your overall level of satisfaction with the } \\
\text { number of SAP ECC assignments in the SAP ERP course? (7) }\end{array}$ & 87 \\
\hline $\begin{array}{l}\text { Which of the following best describes your overall level of satisfaction with the } \\
\text { enterprise software content in the SAP ECC course? (8) }\end{array}$ & 83 \\
\hline $\begin{array}{l}\text { The SAP ERPsim simulations took more time and effort than its expected worth to me } \\
\text { in better understanding and applying integrated business processing concepts. (5) }\end{array}$ & 53 \\
\hline
\end{tabular}

Table 3 highlights student satisfaction with the use of the SAP ECC enterprise software on several fronts-the learning and depth of learning regarding the SAP ECC system and enterprise software, integrated business processes and data-driven business decision-making. Overall, about $80 \%$ of the participants were satisfied with the way the SAP ERP enterprise software and the SAP ERPsim simulator were used in the class as well as during their class time. This is an important indicator of the positive reception of the enterprise software and the simulator as teaching tools. On the other hand, students had mixed opinions on the amount of effort required for the course in this learning experience. Fifty-three present expressed their opinion of satisfaction of the course workload in their responses to questions 5 and 10 . For question 5, 39\% thought the course was too much work, whereas for question $10,34 \%$ viewed the course workload as too great concerning the understanding of the experience with the integration of business processes. A comment from the students was "the course is good for us to learn more about the integration of the concepts and ideas of the functional areas of business from marketing, finance and management." Other students' comments suggested that they learned more with the software and simulator.

Table 3. Student Satisfaction with the SAP ECC Enterprise Software

\begin{tabular}{|l|c|}
\hline \multicolumn{1}{|c|}{ Item (Survey question number) } & \% Satisfied \\
\hline $\begin{array}{l}\text { Which of the following best describes your overall level of satisfaction with the SAP } \\
\text { ECC software assignments used in the SAP ECC course in understanding integrated } \\
\text { business processes? (12) }\end{array}$ & 79 \\
\hline $\begin{array}{l}\text { Which of the following best describes your overall level of satisfaction with the SAP } \\
\text { ECC in learning about the integration of business transaction processing with business } \\
\text { decision-making? (13) }\end{array}$ & 82 \\
\hline $\begin{array}{l}\text { Which of the following best describes your overall level of satisfaction with the depth } \\
\text { of learning regarding the SAP ECC system and enterprise software in the SAP ERP } \\
\text { course? (14) }\end{array}$ & 78 \\
\hline $\begin{array}{l}\text { The SAP ECC software assignments took more time and effort than its expected worth } \\
\text { to me in better understanding and applying integrated business processing concepts. } \\
\text { (10) }\end{array}$ & 53 \\
\hline $\begin{array}{l}\text { Which of the following best describes your overall level of satisfaction with the } \\
\text { number of class hours for this course? (24) }\end{array}$ & 85 \\
\hline
\end{tabular}


Table 4 lists the students' satisfaction with the SAP ECC software assignments. Here, $83 \%$ agreed that the SAP ECC software assignments were instrumental in enhancing their understanding of the issues and concepts associated with the way transaction processing occurred in enterprise software. In the typical face-to-face lecture-based only classroom, the instructor would have to use up plenty of class time to explain the business processes required by transactions. A similar number of students stated that the SAP ECC software assignments also enhanced their understanding of the integrated nature of business transaction processing. This highlights the fact that carefully designed assignments do help with student learning.

Table 4. Impact of SAP ECC Business Transactions on Student Learning

\begin{tabular}{|l|c|}
\hline \multicolumn{1}{|c|}{ Item (Survey question number) } & \% Agree \\
\hline $\begin{array}{l}\text { The SAP ECC software assignments helped me better understand the issues, concepts, } \\
\text { and ideas of transaction processing that takes place in enterprise software. (9) }\end{array}$ & 83 \\
\hline $\begin{array}{l}\text { The SAP ECC software assignments helped me better understand how integrated } \\
\text { business transaction processing works to support the actions resulting from business } \\
\text { decision-making. (11) }\end{array}$ & 83 \\
\hline
\end{tabular}

Questions 16, 17, 18, 19 and 20 (Table 5) refers to the students working in their teams. More than $92 \%$ of the students agree that working in teams helped with their learning and communication. This finding is not a surprise since students often express a preference to work in teams and prefer to help their classmates instead of just working individually. On the other hand, only $28 \%$ indicated a preference for working individually, whereas $66 \%$ indicated working in teams would be better. The remaining $6 \%$ were indifferent in completing their assignments individually.

Table 5. Teamwork Outcome Measures

\begin{tabular}{|l|c|}
\hline \multicolumn{1}{|c|}{ Item (Survey question number) } & \% Agree \\
\hline $\begin{array}{l}\text { Working in teams in the SAP ERP course helped me improve my effectiveness as a } \\
\text { team member in completing the team assignments in other courses (16) }\end{array}$ & 93 \\
\hline $\begin{array}{l}\text { Overall, the teamwork in all my courses helped improve my communication and other } \\
\text { skills in working as a team solving business problems (17) }\end{array}$ & 92 \\
\hline Our team worked together effectively on the SAP ECC Global Bike assignments. (18) & 95 \\
\hline Our team worked together effectively on the SAP ERPsim simulations (19) & 98 \\
\hline $\begin{array}{l}\text { Completing all assignments individually in the SAP IBE course would be better than } \\
\text { working on them as a team. (20) }\end{array}$ & 28 \\
\hline
\end{tabular}

When the participants were asked whether the size of the teams should be changed, $83 \%$ stated that the current size of five (5) is about right (Table 6). About $15 \%$ indicated that it should be decreased and only $2 \%$ felt that it should be increased. These results were supported by survey question number 22 which asked the participants for their suggestions regarding the optimal team size for the SAP ERP course. The majority of the participants indicated that their team sizes were optimal for this learning experience. Overall, students also liked the fact that these learning tools require them to work in teams more effectively and efficiently. They believe that their communications as team members also had improved. Comments from the students include "It is really an interesting course! Not only knowledge, but also teamwork. I enjoy this course very much.”

Table 6. Team Sizes

\begin{tabular}{|l|c|c|c|}
\hline \multicolumn{1}{|c|}{ Item (Survey question number) } & $\begin{array}{c}\text { \% It should } \\
\text { be increased }\end{array}$ & $\begin{array}{c}\text { \% It is just } \\
\text { about right }\end{array}$ & $\begin{array}{c}\text { \% It should } \\
\text { be decreased }\end{array}$ \\
\hline $\begin{array}{l}\text { What is your opinion about the size of the teams used in } \\
\text { this SAP IBE course (that is, the number of team } \\
\text { members) (21) }\end{array}$ & 2 & 83 & 15 \\
\hline
\end{tabular}


A summary across the four dimension (Table 7) indicates an overall evaluation impact of $86 \%$, which is viewed by the authors as a most successful delivery of this approach to integrated business processes. This measure does not include measures of student perceptions of the amount of work in completing the course as that represents their impression of the workload of this course versus other courses in the curriculum. Teamwork dimension was the strongest area of student agreement. This is an area of emphasis across the entire BSBA curriculum and demonstrates the effective inclusion of that component in this course.

Table 7. Overall Impact by Category

\begin{tabular}{|l|c|}
\hline \multicolumn{1}{|c|}{ Category } & $\begin{array}{c}\text { \% Agree } \\
\text { Average }\end{array}$ \\
\hline Business Integration & 86 \\
\hline Business Transactions & 82 \\
\hline Teamwork & 89 \\
\hline Student Satisfaction & 84 \\
\hline Overall Evaluation & 86 \\
\hline
\end{tabular}

\section{SUMMARY AND CONCLUSIONS}

These results suggest that using the SAP ECC enterprise software and the SAP ERPsim simulations can enhance the learning of the integration of business processes, their related transactions, and decision-making. Overwhelmingly, the students were most satisfied with the model course organization and its delivery using the technological landscape with the multiple servers of the ERPsim environment.

A number of lessons have been learned through this experience of the IBE course delivery. Key lessons learned are as follows:

1. The technology environment was not a challenge. Access to the SAP ECC and ERPsim servers was readily available and maintained consistence communication connections.

2. The model course organization worked extremely well as is validated by the student perceptions of the course.

3. The goal of the course for students to understand enterprise software and its use in the day-to-day integrated operations of a business organization was achieved.

4. The goal of the course for students to understand the application and use of enterprise software in decisionmaking across the functional business areas was achieved.

5. The course described here serves as an approach that may be used in a corporate training environment.

The technological architecture and model course organization should be tested in other CBKs of the BSBA degree to determine the efficacy of the approach on a broader scale. Future work should examine the use of only one dataset across the entire learning model organization. That is, one dataset or client for both learning the fundamental operational level transactions and the ERPsim business decision-making environment. This would reduce the requirement for students to shift their thinking from one type of business, such as GBI with its data, to another type of business with different data, such as the manufacture of cereal as used with the ERPsim simulation.

\section{REFERENCES}

1. Antonucci, Y. L., Corbitt, G., Stewart, G. and Harris, A. L. (2004). Enterprise Systems Education: Where Are We/ Where Are We Going? Journal of Information Systems Education, 15(3), 227-234.

2. Hayen, R. L. (1997) SAP R/3 enterprise software: an introduction, New York, NY: McGraw-Hill Irwin.

3. Hayen, R. L. (2013). SAP Enterprise Software Introductory Course: A New Paradigm, Proceedings $53^{\text {rd }}$ IACIS Conference, 54-55.

4. Hayen, R. L. \& Holmes, M. C. (2013). [SAP Integrated Business Processes]. Raw research data.

5. Hayen, R. L., Vetter, D., \& Huang, Z. (2007). Using ERP in Curriculum Integration: A Case Study. Issues in Information Systems, 8(1), 204-210. 


\section{Issues in Information Systems}

Volume 15, Issue I, pp. 141-148, 2014

6. HEC Montreal. (2013). ERPsim Lab. Available: http://erpsim.hec.ca/learning/ April 17, 2013.

7. Johnson, T., Lorents, A. C., Morgan, J., \& Ozmun, J. (2004). A customized ERP/SAP model for business curriculum integration. Journal of Information Systems Education, 15(3), 245-253.

8. Kappelman, L.A. \& Zachman, J.A. (2013) The Enterprise and Its Architecture: Ontology \& Challenges. Journal of Computer Information Systems, 53(4), 87-95.

9. Reid, J. \& Anderson, P. (2012) Critical Thinking in the Business Classroom. Journal of Education for Business, 87: 52-59

10. Rosemann, M., \& Maurizio, A. A. (2005). SAP-related education - status quo and experiences. Journal of Information Systems Education, 16(4), 437-453.

11. SAP AG University Alliance. (2013) Introduction to SAP ERP using Global Bike Inc. 2.11. Available: https://cw.sdn.sap.com/cw/docs/DOC-153068.

12. Williams, S.L. (2011). Engaging values in international business practice. Business Horizons, 54, 315-324

13. Xu, Y. \& Yang, Y. (2010). Student learning in Business Simulation. Journal of Education for Business, 85(4), 223-228.

14. Weidner, S. (2012). Global Bike Inc. 2.11, SAP University Alliances. 